\title{
HUBUNGAN GAYA BELAJAR DENGAN KELULUSAN UJIAN BLOK PADA MAHASISWA FAKULTAS KEDOKTERAN UNIVERSITAS ABULYATAMA
}

\author{
Ade Kiki Riezky ${ }^{1}$, Rauza Akmalia ${ }^{1}$ \\ ${ }^{1}$ Fakultas Kedokteran Universitas Abulyatama
}

\begin{abstract}
The Relationship Between Learning Style and Exam Passing Score in Undergraduated Medical Student at Faculty of Medicine Abulyatama University. Every people have their own learning style. Learning process will be effective when student knows their learning style. The purpose of this study is to know the type of students learning style and its relationship to block exam. This study uses cross sectional approached and collecting data have done in 2016 . The population is under graduated medical student at faculty of medicine, Abulyatama University. The sample is 200 students which taken by simple random sampling technique. Collecting data was take by VARK questionnaire and block exam result form student assessment department. Data Analysis in this study using chi square. The result shows that student who have audio learning style are 68, the student who have visual learning style are 64, the student who have kinesthetic learning style are 61 , and the student who have read learning style are 7 . Chi-square shows that a value is $0,870(a<0,05)$. The conclusion is no relationship between learning style and exam passing score.
\end{abstract}

Keywords: learning style, under-graduated student, student perform.

\begin{abstract}
Abstrak : Hubungan Gaya Belajar dengan Kelulusan Ujian Blok pada mahasiswa Fakultas Kedokteran Universitas Abulyatama. Setiap orang memiliki gaya belajar yang berbeda-beda. Proses belajar akan lebih efektif dan efisien ketika mahasiswa mampu memahami gaya belajarnya. Tujuan penelitian ini adalah untuk mengetahui jenis gaya belajar mahasiswa dann mengetahui hubungan antara gaya belajar mahasiswa dengan tingkat kelulusan ujian blok. Penelitian ini pendekatan cross sectional. Penelitian dilakukan pada bulan januari 2016. Populasi penelitian ini adalah mahasiswa pendidikan dokter Fakultas Kedokteran Universitas Abulyatama. Sampel diambil menggunakan teknik random sampling.Sampel penelitian berjumlah 200 orang. Teknik pengumpulan data menggunakan kuesioner VARK dan data hasil ujian blok. Analisa data dalam penelitian ini menggunakan analisa chi kuadrat. Hasil penelitian memperlihatkan mahasiswa pendidikan dokter Fakultas Kedokteran Universitas Abulyatama mempunyai gaya belajar audio 68 mahasiswa, gaya belajar visual 64 mahasiswa, gaya belajar kinestetik 61 mahasiswa, dan gaya belajar membaca 7 mahasiswa. Hasil chi-square test didapat nilai a 0,870 (a<0,05). Kesimpulan penelitian yaitu tidak ada hubungan antara gaya belajar dengan tingkat kelulusan ujian blok.
\end{abstract}

Kata kunci : gaya belajar, mahasiswa tahap akademik, performa mahasiswa

PENDAHULUAN

Metode pembelajaran di

fakultas-fakultas kedokteran di

Indonesia, menganut metode problem

based learning (PBL). (Liansyah, 2015). PBL menekankan pada student centered learning, pembelajaran aktif dan belajar mandiri (Amin and Khoo, 2012).

Mahasiswa dituntut lebih aktif dalam mempelajari suatu materi berdasarkan masalah, dan mendorong mereka untuk belajar secara mandiri dari segala sumber (Dent, Harden, Hunt, 2013). Bahkan sekarang 
dengan perkembangan teknologi yang begitu pesat, terutama dalam bidang pendidikan membuat akses akan ilmu pengetahuan dan informasi dapat didapatkan dengan mudah dan cepat (Ghafari, 2013). Setiap mahasiswa pastinya mempunyai gaya tersendiri dalam belajar. Mahasiswa akan dapat mengintegrasikan dan menyesuaikan dengan proses belajar, sehingga mereka akan cepat, mudah, dan berhasil dalam menyerap informasi atau pelajaran (Hardiansyah, 2014).

Gaya belajar dapat diartikan sebagai komposit dari kognitif, afektif dan fisiologis karakteristik yang berfungsi sebagai indikator yang relatif stabil terhadap bagaimana seorang mahasiswa merasakan, berinteraksi dan merespon lingkungan belajarnya (Almiqbal, 2015).

Gaya belajar paling banyak dan mudah digunakan adalah gaya belajar Visual, Audio, Read, and Kinesthetik (VARK) yang dicetus oleh Neil Fleming. Tipe gaya belajar visual adalah tipe gaya belajar yang menerima dan memahami informasi dengan cara melihat. Tipe gaya belajar audio adalah gaya belajar dengan cara mendengar. Tipe gaya belajar read/write akan suka belajar dengan cara membaca, menulis, membuat grafik, atau skema. Tipe gaya belajar kinestetik belajar dengan cara melakukan sesuatu yang dipelajarinya (Lisiswanti, 2014). Namun pada dasarnya setiap orang memiliki keempat gaya belajar tersebut, akan tetapi hanya salah satu gaya yang biasanya lebih mendominasi (Nurhidayah, 2010).

Sebagian besar gaya belajar mahasiswa Fakultas Kedokteran Universitas Diponegoro adalah visual dan audio. Kedua gaya tersebut termasuk ke dalam tipe gaya unimodal (hanya satu gaya belajar yang lebih dominan). Selain itu, diperoleh juga bahwa tidak ada pengaruh gaya belajar unimodal terhadap prestasi akademik mahasiswa. Akan tetapi untuk gaya belajar multimodal (mempunyai lebih dari satu gaya belajar yang lebih dominan), mempunyai pengaruh positif terhadap prestasi akademik mahasiswa (Hardiansyah, 2014).

Gaya belajar yang paling banyak digunakan oleh mahasiswa Fakultas Kedokteran Universitas Lampung adalah audio. Gaya belajar tersebut mempunyai hubungan sangat positif antara gaya belajar dengan prestasi akademik mahasiswa (Lisiswanti, 2014). Gaya belajar model VARK juga digunakan hampir sebagian mahasiswa kedokteran di Universitas King Saud. Penelitian dibeberapa negara khususnya yang dilakukan di Universitas King Saud Arab Saudi dan Universitas Of Medical Sciences Iran, tidak menunjukkan hubungan yang signifikan antara gaya belajar dengan prestasi akademik (Almiqbal, 2015).

Dalam proses belajar tidak ada gaya belajar yang dianggap benar atau salah, karena setiap orang mempunyai gaya belajar berbedabeda yang memberikan keuntungan serta kekurangan masing-masing. Ketika mahasiswa mampu memahami gaya belajarnya, maka proses belajar mahasiwa akan lebih efektif dan efisien (Hardiansyah, 2014).

Salah menerapkan gaya belajar dapat menyebabkan kegagalan dan frustasi pada mahasiswa (Lisiswanti, 2014). Untuk mengetahui gaya belajar masing-masing mahasiswa maka diperlukan pembahasan lebih lanjut mengenai gaya belajar yang lebih detail dan langkah-langkah apa yang dapat mahasiswa ambil untuk memilih strategi belajar yang sesuai dengan gaya belajar yang mereka miliki. Oleh karena itu, penelitian ini dirancang untuk mengetahui gaya belajar terhadap tingkat kelulusan ujian blok mahasiswa jurusan pendidikan dokter Fakultas Kedokteran Universitas Abulyatama (FK Unaya).

\section{METODE}

Jenis Penelitian yang digunakan adalah analitik dengan desain cross sectional. Penelitian dilakukan di FK Unaya pada bulan Maret - Juni 2016. Sampel penelitian adalah mahasiswa program studi 
pendidikan dokter FK Unaya. Sampel diambil menggunakan teknik random sampling. Data primer diambil menggunakan kuesioner VARK, sedangkan data sekunder diambil melalui bagian student assessment. Analisis data menggunakan uji chi square.

\section{HASIL DAN PEMBAHASAN}

Gaya belajar dalam penelitian ini dikelompokkan menjadi 4 golongan, yaitu visual, audio, read, dan kinestetik. Masing-masing gaya belajar memiliki kategori khusus yang telah dicantumkan dalam kuesioner.

\section{Jenis Gaya Belajar}

Pada tabel 1, dapat disimpulkan gaya belajar mahasiswa program studi pendidikan dokter FK Unaya adalah sebagai berikut :

Tabel 1. Jenis Gaya Belajar Dominan Mahasiswa FK Unaya

\begin{tabular}{cccc}
\hline No. & Gaya Belajar & Frekuensi & Persentase \\
\hline 1. & Audio & 68 & $34 \%$ \\
2. & Kinestetik & 61 & $30,5 \%$ \\
3. & Membaca & 7 & $3,5 \%$ \\
4. & Visual & 64 & $32 \%$ \\
\hline & Total & 200 & $100 \%$
\end{tabular}

Sumber: data primer diolah tahun 2016

Tabel 1 menjelaskan bahwa mayoritas responden dengan gaya belajar audio sebanyak 68 orang $(34 \%)$, gaya belajar visual sebanyak 64 orang $(32 \%)$, gaya belajar kinestetik sebanyak 61 orang $(30,5 \%)$, sedangkan dengan gaya belajar membaca hanya 7 orang $(3,5 \%)$.
Tingkat Kelulusan Ujian Blok

Tingkat kelulusan ujian blok mahasiswa jurusan program studi pendidikan dokter FK Unaya dapat dilihat pada Tabel 2. Data penelitian digolongkan menjadi 2 golongan yaitu lulus dan tidak lulus.

Tabel 2. Tingkat Kelulusan Ujian Blok Mahasiswa FK-Unaya

\begin{tabular}{lccc}
\hline No & Tingkat Kelulusan & Frekuensi & Persentase \\
\hline 1. & Lulus & 181 & $90,5 \%$ \\
2. & Tidak lulus & 19 & $9,5 \%$ \\
\hline \multicolumn{4}{c}{ Total } \\
\hline \multicolumn{2}{c}{ Sumber : bagian student assessment FK Unaya }
\end{tabular}

Tabel 2 menjelaskan tingkat kelulusan ujian blok Gangguan Sistem Endokrin dan Metabolisme, Gastrointestinal dan Hepatopankreato-bilier, serta Sistem Urogenitalia mahasiswa FK Unaya. Bahwa dinyatakan lulus sebanyak 181 orang $(90,5 \%)$, dan yang dinyatakan tidak lulus sebanyak 19 orang $(9,5 \%)$.

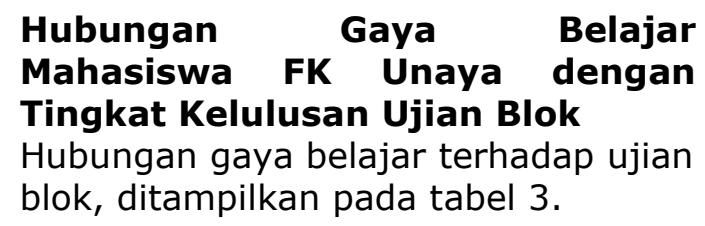


Tabel 3. Hubungan Gaya Belajar Mahasiswa FK Unaya dengan Tingkat Kelulusan Ujian Blok

\begin{tabular}{|c|c|c|c|c|c|c|c|c|}
\hline \multirow[t]{2}{*}{ No. } & \multirow{2}{*}{$\begin{array}{c}\text { Tingkat } \\
\text { Kelulusan }\end{array}$} & \multicolumn{4}{|c|}{ Gaya belajar } & \multirow[t]{2}{*}{ Total } & \multirow[t]{2}{*}{$\boldsymbol{a}$} & \multirow{2}{*}{$\begin{array}{c}\text { P- } \\
\text { value }\end{array}$} \\
\hline & & Audio & Kinestetik & $\begin{array}{l}\text { Mem } \\
\text { baca }\end{array}$ & Visual & & & \\
\hline 1. & Lulus & 62 & 54 & 6 & 59 & 181 & & \\
\hline 2. & Tidak Lulus & 6 & 7 & 1 & 5 & 19 & 0,05 & 0,870 \\
\hline & Total & 68 & 61 & 7 & 64 & 200 & & \\
\hline
\end{tabular}

Sumber : data primer, diolah tahun 2016

Tabel 3 menjelaskan mahasiswa yang lulus ujian blok dengan gaya belajar audio sebanyak 62 orang $(30 \%)$, gaya belajar kinestetik 54 orang $(27 \%)$, gaya belajar membaca 6 orang $(3 \%)$ dan gaya belajar visual $59(29,5 \%)$. Responden yang tidak lulus ujian blok dengan gaya belajar audio 6 orang $(3 \%)$, gaya belajar kinestetik 7 orang $(3,5 \%)$, gaya belajar membaca 1 orang $(0,5 \%)$, dan gaya belajar visual 5 orang (2,5\%).

Hasil penelitian ini juga sejalan dengan penelitian Nuniek Pradita Sari, pada penelitian tersebut tidak ada hubungan yang signifikan antara gaya belajar dengan prestasi siswa dalam mata pelajaran matematika. Faktor yang menyebabkan ditolaknya hipotesis penelitian tersebut karena penelitian dilakukan pada saat jam pelajaran terakhir sehingga menyita perhatian para siswa untuk sekedar memenuhi kewajiban mengisi skala dan segera pulang, sehingga subjek terburu-buru saat mengisi skala. Penyebab lain adalah siswa kurang memahami isi kuesioner, sehingga jawaban yang diberikan tidak berdasarkan kenyataan (Nuniek ,2014).

Hasil penelitian yang serupa juga diperoleh pada penelitian di Tehran Irak oleh Ghaffari et al, bahwa tidak ada hubungan yang signifikan antara gaya belajar dengan prestasi belajar mahasiswa kedokteran (Ghafari, 2013). Penelitian di Arab Saudi oleh Almiqbal Turky, menyatakan tidak ada hubungan yang signifikan antara gaya belajar dengan prestasi belajar namun didapat hasil yang signifikan antara gaya belajar dengan jenis kelamin (Almiqbal, 2015).

Gaya belajar secara langsung mempengaruhi perilaku belajar mahasiswa, dan secara tidak langsung mempengaruhi tingkat kelulusan ujian blok. Beberapa aspek tingkat kelulusan blok yang dipengaruhi oleh gaya belajar yaitu modalitas dan dominasi otak (Hardiansyah, 2014).

Gaya belajar mengacu pada cara belajar yang lebih disukai mahasiswa. Gaya belajar seseorang berasal dari kepribadian individu, termasuk susunan kognitif dan psikologis, latar belakang sosiokultural, dan pengalaman pendidikan. Keanekaragaman gaya belajar mahasiswa perlu diketahui pada awal permulaannya diterima pada suatu universitas yang akan Ia jalani. Hal ini akan memudahkan mahasiswa untuk belajar, dan dosen untuk mengajar dalam proses pembelajaran. Mahasiswa akan dapat belajar dengan baik dan hasil belajarnya baik, apabila Ia mengerti gaya belajarnya. Mahasiswa dapat menerapkan pembelajaran dengan mudah dan tepat jika mereka paham gaya belajar masing-masing. Gaya belajar mahasiswa satu dengan mahasiswa yang lainnya akan berbeda-beda, masing-masing mahasiswa memiliki cara pandang tersendiri terhadap 
setiap peristiwa yang dilihat dan dialami (Bukit, 2015).

Gaya belajar memang tidak secara langsung menjadi faktor-faktor yang mempengaruhi tingkat kelulusan blok, namun gaya belajar merupakan suatu kemampuan dasar seorang mahasiswa dalam menerima, kemudian menyimpan dan mengolah informasi yang Ia dapatkan. Jika kita analogikan, setiap mahasiswa dengan perbedaan dari setiap gaya belajar memiliki perbedaan dalam cara mengingat pula.

Pada mahasiswa dengan gaya belajar yang dominan audio, Ia akan lebih mengingat suara yang didengar saat proses pembelajaran berlangsung. Gaya belajar audio mengandalkan pada pendengaran untuk bisa memahami dan mengingatnya. Karakteristik model belajar seperti ini menempatkan pendengaran sebagai alat utama menyerap informasi atau pengetahuan. Itulah mengapa mahasiswa dengan gaya belajar audio lebih mudah terpecah konsentrasinya bila terdapat suatu kebisingan (Nuniek, 2014) dan (Bukit, 2015).

Mahasiswa dengan gaya belajar yang dominan visual, Ia akan mengingat gambar dan tulisan yang dipelajari. Gaya belajar visual menitik beratkan pada ketajaman penglihatan, mengandalkan penglihatan atau melihat dulu buktinya untuk kemudian bisa mempercayainya.

Gaya belajar kinestetik lebih mengingat pada proses. Ia lebih memahami bila apa yang ada dalam buku teks, telah di tungkan dalam praktek sehari-hari. Gaya belajar

\section{DAFTAR PUSTAKA}

Almiqbal H.Turky. 2015. Relationship Between The Learning Style Preferences of Medical Students and Academic Achievement, Jurnal Saudi Med, Volume 36, Nomor 3. kinestetik mengharuskan seorang mahasiswa yang bersangkutan untuk menyentuh atau mensimulasikan sesuatu yang memberikan informasi tertentu agar Ia bisa mengingatnya (Bukit, 2015).

Mahasiswa dengan gaya belajar read yang dominan menekankan pada input dan output berupa bacaan atau tulisan dalam segala bentuk. Mahasiswa yang memiliki karakter belajar ini menyukai daftar, kamus, dan bentuk kata-kata lainnya.

Gaya belajar mahasiswa tidak dapat diubah, namun setelah mahasiswa mengerti gaya belajarnya, diharapkan mahasiswa dapat memaksimalkan gaya belajar yang Ia miliki dengan cara belajar yang sesuai dengan gaya belajarnya masingmasing (Bukit, 2015).

\section{Keterbatasan penelitian}

Kekurangan penelitian ini disebabkan oleh responden kemungkinan menjawab pertanyaan-pertanyaan kuesioner yang diberikan oleh peneliti tidak sesuai dengan yang dimaksud oleh peneliti sebenarnya sehingga mempengaruhi hasil penelitian. Selain gaya belajar, banyak faktor lain yang mempengaruhi tingkat kelulusan ujian blok mahasiswa.

\section{KESIMPULAN}

Berdasarkan tabel 3 dapat diketahui hasil analisis chi-square test didapatkan nilai $a$ 0,870. Sedangkan nilai $a$ tabel dengan signifikansi $5 \%$ adalah 0,05 . Kesimpulan penelitian ini yaitu tidak ada hubungan antara gaya belajar dengan tingkat kelulusan ujian blok.

Bukit Sriwati, Istarani. 2015 Kecerdasan \& Gaya Belajar, Larispa Indonesia: Medan.

Ghaffari Reza, et al. 2013. The Analysis of Learning Style and Their Relationship to Academic Achievement in Medical Students of Basic Sciences 
Program, Jurnal Res Dev Med Educ, Volume 2, Nomor 2.

Hardiansyah. 2014. Pengaruh Gaya Belajar Terhadap Prestasi Akademik Mahasiswa Fakultas Kedokteran. Universitas Diponegoro : Semarang.

John A Dent, Ronald M Hardent, dan Hunt. 2013. A Practical Guide for Medical Teacher. Elsevier: China.

Liansyah Menawati Tita. 2015. Problem Based Learning Sebagai Metode Perkuliahan Kedokteran Yang Efektif, Jurnal Pedagogik, Volume 8, Nomor 1.

Lisiswanti Rika. 2014. The Relationship Learning Style and Student's Achievement of
Lampung University Faculty of Medicine, Jurnal Juke, Volume 4, Nomor 7.

Nurhidayah Endah Rika. 2010. Learning Styles Characteritic and Learning Outcomes of Nursing Faculty Students of University of Sumatera Utara, Universitas Sumatera Utara: Medan.

Sari Pradita Nuniek. 2014. Pengaruh Gaya Belajar Terhadap Prestasi Belajar Matematika Siswa, Universitas Ahmad Dahlan, Yogyakarta.

Zubair Amin, Khoo Hoon Eng. 2012. Basic in Medical Education. World scientific publishing; Singapore. 